\title{
Regional based estimates of water use for commercial sugar-cane in South Africa
}

\author{
CN Bezuidenhout ${ }^{1 *}$, NL Lecler ${ }^{2}$, C Gers $^{2}$ and PWL Lyne ${ }^{2}$ \\ ${ }^{1}$ School of Bioresources Engineering \& Environmental Hydrology, University of KwaZulu-Natal, Private Bag X01, \\ Scottsville 3209, South Africa \\ ${ }^{2}$ South African Sugarcane Research Institute, Private Bag x02, Mt Edgecombe 4300, South Africa
}

\begin{abstract}
The water use of rain-fed sugar-cane has come under the spotlight in South Africa, largely as a result of changes in legislation and a focus on streamflow reduction activities. In this study a robust relationship between sugar-cane yield and evapotranspiration derived by Thompson in 1976 is applied in conjunction with regional cane production records in South Africa. These were used to provide regional estimates of water use of commercial rain-fed and irrigated sugar-cane as affected by environmental limitations. The mean water use of sugar-cane at an industry scale was $598 \mathrm{~mm} \cdot \mathrm{a}^{-1}$. This included irrigated cane and is approximately $40 \%$ of the mean industry potential evapotranspiration for a full canopy crop. An estimate of water use of rain-fed cane is approximately $36 \%$ of potential evapotranspiration. The results shown in this paper provide strong evidence that simple comparisons of the potential evapotranspiration of different crops or land covers are of little value in determining potential hydrological impacts of land-use changes. This illustrates that the use of potential sugar-cane evapotranspiration to compare this crop's impacts on streamflow reduction to those of original vegetation is a problematic approach and is fundamentally flawed.
\end{abstract}

Keywords: water use, sugar-cane, regional production, evapotranspiration, Thompson model

\section{Introduction}

The water use of rain-fed sugar-cane has come into focus in South Africa, largely as a result of changes in legislation. In the new South African Water Act (Act 36 of 1998), definitions of water use have been extended to include: 'engaging in a streamflow reduction activity' (SFRA). An SFRA is defined in Section 36 of the Water Act as any activity, including the cultivation of any particular crop or vegetation which in relation to a particular area, has a significant impact on water availability to other users, including the Reserve. To date, forestry is the only declared SFRA; however, in light of the new Water Act, other crops or land covers have come under the spotlight as potential SFRAs.

In an influential study, Kruger et al. (2000) adopted a methodology whereby candidate SFRAs were determined based largely on a comparison of their potential evapotranspiration (PET) rates with the PET rates of corresponding Acocks veld types (Acocks, 1975). In this study Kruger et al. (2000) reported that the PET of sugar-cane was approximately $1400 \mathrm{~mm} \cdot \mathrm{a}^{-1}$, compared to corresponding country-wide average PET rates of Acocks veld types of approximately $1100 \mathrm{~mm} \cdot \mathrm{a}^{-1}$. As a result, it was concluded that sugar-cane should be targeted for further investigation as a potential SFRA.

Estimates of the PET of a crop assume ideal growing conditions and no soil water limitations. However, in reality, growing conditions are seldom ideal and as a result the actual water use/evapotranspiration of a crop (AET), which represents the real water use, is very different to the PET. In addition, the AET of different crops can be very similar when grown under water limited conditions, such as in shallow soils, despite large differences in PET rates. An analogy is to consider several

* To whom all correspondence should be addressed.

욜 +27332605703 ; fax: +27332605818 ;

e-mail: bezuidenhoutc@ukzn.ac.za

Received 22 August 2005; accepted in revised form 17 January 2006. reservoirs, each containing the same amount of water. If the water in each of these reservoirs is pumped out with different sized pumps, the same total amount of water will be pumped, independent of the pump sizes, provided the reservoirs are not replenished. Therefore, if sugar-cane could potentially consume $1400 \mathrm{~mm} \cdot \mathrm{a}^{-1}$ (a relatively larger pump in the analogy) and the Acocks veld type it replaces could potentially consume $1100 \mathrm{~mm} \cdot \mathrm{a}^{-1}$ (a relatively smaller pump in the analogy), but only $700 \mathrm{~mm} \cdot \mathrm{a}^{-1}$ is available (the amount of reservoir water available for pumping in the analogy), then both vegetation covers are likely to consume close to $700 \mathrm{~mm} \cdot \mathrm{a}^{-1}$. AET is therefore similar for both crops, and significantly less than PET, since AET will be limited by the amount of water available. This is simplistic, but it does highlight the fact that actual water use and potential hydrological impacts of different crops is complex and probably more dependent on limitations imposed by specific growing environments and rooting conditions, rather than a comparison of PET rates.

The key question, therefore, should be to establish the AET of sugar-cane (rather than the PET) in the different regions where this crop is grown. Currently research studies are underway whereby actual water use or AET of sugar-cane is measured using remote sensing techniques (e.g. Hemakumara et al., 2003). Results from these and similar studies are, however, site and season specific and cannot be simply extrapolated to other conditions without limitations.

In this study a robust relationship between sugar-cane yield and AET derived by Thompson (1976) is applied in conjunction with historical cane yield records from mill areas in South Africa in order to give regional estimates of the actual water use of sugar-cane as affected by environmental limitations.

\section{Methodology}

During a sugar-cane water use study, Thompson (1976) derived a robust relationship between sugar-cane yield and AET. This linear relationship, given in Eq. (1), was based on a compari- 
son of in-field measurements of AET and cane yields using data from Hawaii, Australia, Mauritius and several locations in South Africa.

$$
\text { Yield }=9.53 \frac{\Sigma E_{P}}{100}-2.36
$$

where:

$$
\begin{aligned}
& \Sigma E_{P}(\mathrm{~mm}) \text { is total AET since crop initiation } \\
& \text { Yield }\left(\mathrm{t} \cdot \mathrm{ha}^{-1}\right) \text { is cane yield }
\end{aligned}
$$

Equation (1) is well representative in the typical harvesting windows of commercial sugar-cane crops in South Africa. It has provided a benchmark for several subsequent research studies related to sugar-cane water use and biomass production (e.g. Coombs, 1984; Schulze, 1995; Lumsden et al., 1998; Singels and Bezuidenhout, 2002) and has since been widely referenced and acknowledged by researchers all over the world, including Brazil (Scarpari and De Beauclair, 2004), Australia (Muchow et al., 1994; Robertson et al., 1996; Evensen et al., 1997), Thailand (Brzesowsky and Van Vilsteren, 1988), the USA (Legendre and Burner, 1995) and Mauritius (Cheeroo-Nayamuth et al., 2000).

Regional production data from 1979 to 2002 were collated for the 15 sugar mills that were operational in 2002 (data courtesy of the SA Cane Growers Association). This information contained the total cane crushed at a mill per annum $\left(C\right.$ in $\left.t \cdot \mathrm{a}^{-1}\right)$, the total area under sugar-cane farming ( $A$ in ha) and the total area harvested per annum $\left(H\right.$ in ha $\left.\cdot \mathrm{a}^{-1}\right)$.

Total cane crushed per annum $(C)$ can be regarded as accurate since this information is used to remunerate growers. This figure, however, is an under-estimate of the total tonnage of cane produced in an area. Several factors may cause cane and mass losses before cane reaches the mill. These include:

- Cane grown in seed cane schemes

- Cane spillages in the field, road and mill yard

- Cane mass losses as a result of post-harvest respiration and evaporation (Egan, 1968; Lionnet, 1986; Wood and Du Toit, 1972).

The above-mentioned were estimated at $2 \%, 1 \%$ and $2 \%$ of total annual cane production, respectively (SASRI Extension Department, 2005). The value of $C$, therefore, needs to be inflated by $5 \%$, which is done later in Eq. (3).

Estimates of areas $(A$ and $H)$ are less reliable compared to $C$ (Wynne, 2001). This is due to unannounced changes to land-use activities, especially under small-scale enterprises. Small-scale growers, however, contribute less than $20 \%$ of the total annual crop. During calculations of water use, cognizance should be taken of areas left fallow. In this case a conservative estimate of $5 \%$ of $A$ was assumed to be fallow at any time. This value is considered conservative because many growers, especially in recent years, have not followed recommended fallowing practices.

Changes to the industry's milling configuration during the period 1979 to 2002 were considered (Bezuidenhout, 2005). The Nkwaleni and Empangeni Mills were combined with the Felixton Mill in 1985. The coastal Illovo Mill was relocated to Eston in the KwaZulu-Natal midlands in 1994. The Glendale Mill closed in 1997 and cane from that area was redirected to the Gledhow Mill. The Tongaat Mill was renamed to Maidstone Mill in 1982. In 1987 and 1995 new cane was delivered to this mill due to the closure of the Shakas Kraal and Mt. Edgecombe Mills, respectively. In all the above-mentioned cases, data from the different mills were pooled together accordingly.

The average age of harvested cane in a certain year ( $\overline{\mathrm{age}}$ in months) was calculated according to Eq. (2).

$$
\overline{\text { age }}=12 \times \frac{A(1-f)}{H}
$$

where:

$f$ is the fraction of total area left fallow $(f=0.05)$

It should be noted that sugar-cane in South Africa is often grown for longer than 12 months. Therefore, the cane mass produced in one year $\left(C^{\prime}\right.$ in $\left.t \cdot a^{-1}\right)$ can be calculated according to Eq. (3), after which the mean production per hectare per annum $\left(P\right.$ in $\left.\mathrm{t} \cdot \mathrm{ha}^{-1} \cdot \mathrm{a}^{-1}\right)$ can be calculated according to Eq. (4).

$$
C^{\prime}=\frac{12}{\overline{\text { age }}} \times \frac{C}{1-l}
$$

where:

$l$ is the estimated fraction of cane lost before crushing $(l=0.05)$

$$
P=\frac{C^{\prime}}{H}
$$

By using the Thompson model (Eq. (1)), mean annual water use within the mill area $\left(w u\right.$ in $\left.\mathrm{mm} \cdot \mathrm{a}^{-1}\right)$ can be calculated according to Eq. (5).

$$
w u=\frac{100(P+2.36)}{9.53}
$$

\section{Results and discussion}

The mean water use of sugar-cane at an industry scale was $598 \mathrm{~mm} \cdot \mathrm{a}^{-1}$. This is approximately $40 \%$ of the mean annual sugar-cane PET for a full canopy crop, as calculated with the Penman-Monteith equation (McGlinchey and Inman-Bamber, 1996). Figures 1a-e depict probability of non-exceedance plots of $w u$ for the Northern Irrigated, Zululand, KwaZulu-Natal North Coast, Midlands and KwaZulu-Natal South Coast sugar growing regions, respectively. These plots indicate the percentage of seasons, per mill, where $w u$ was below the associated value indicated on the x-axis. Each plot also indicates an estimate of the region's mean annual sugar-cane evaporative demand for a full canopy crop. Mean annual sugar-cane evaporative demands were calculated by Bezuidenhout (2005) using the estimation methodologies of McGlinchey and Inman-Bamber (1996) and Hargreaves and Samani (1985). In Table 1 the mean $w u$ for different mill supply areas is summarised and compared to the mill area's mean annual precipitation. The same values are illustrated in Fig. 2 to depict spatial trends.

Water use in the Northern Irrigated regions, viz. Mpumalanga and Pongola regions, is significantly higher compared to other regions, but is still well below potential water use (Fig. 1a). It should also be noted that $w u$ in these areas is well above mean annual rainfall (MAP, Table 1 and Fig. 2), which clearly indicates the crop's dependency on irrigation. Mill areas in Zululand differ markedly from each other (Fig. 1b). Zululand has a wide range of climatic regions, stretching from high-altitude mistbelt conditions at the Entumeni Mill to flood plain and large irrigated areas at Umfolozi. In the North Coast, Midlands and South Coast regions (Fig 1c-e), water use between mills within the same region was similar. It is noted that water use on the South Coast was similar to those in the Midlands, even though the evaporative demand on the coast is higher. This is probably attributed to:

- Poorer sandy soils and hence more water stress on the coast

- Inclusion of some irrigated cane in the Midlands.

The South Coast is the only region where the influence of irrigated cane on water use estimates could be neglected. The median water use as a percentage of PET in this region is $36 \%$. 

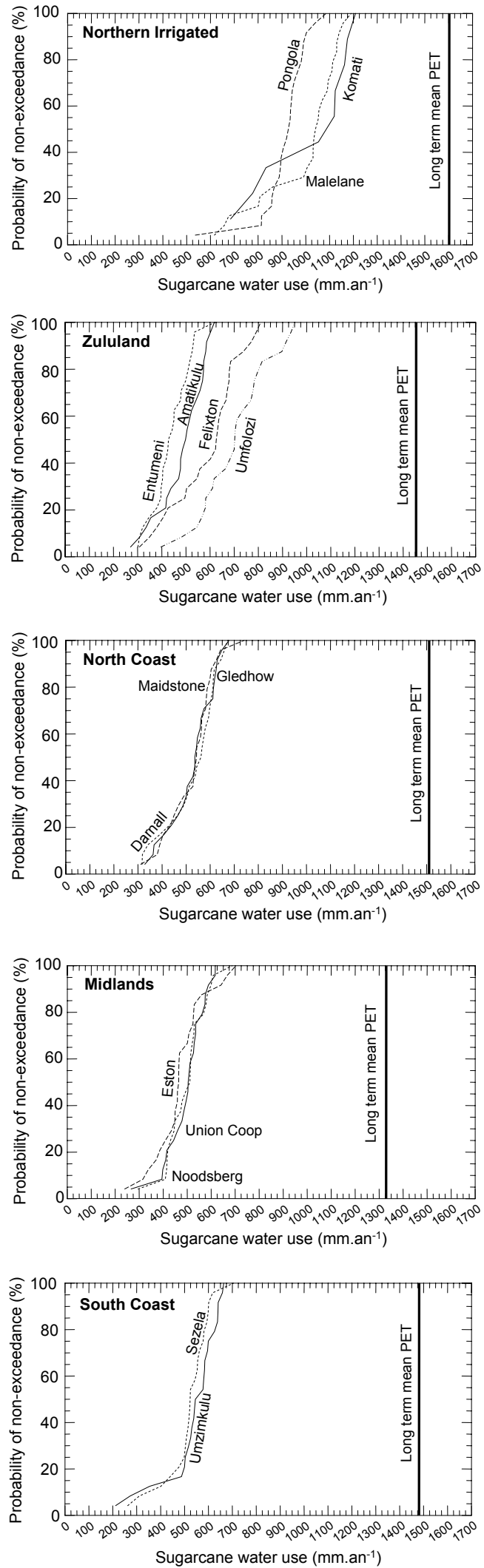

Figure 1

Probability of non-exceedance plots of mean annual regional water use based on the 1978 to 2002 seasons. Different mills and sugar-cane producing regions are plotted separately. Solid lines to the right of these plots depict long-term mean potential water use values (PET) for each region for a full canopy sugarcane crop (McGlinchey and Inman-Bamber, 1996).

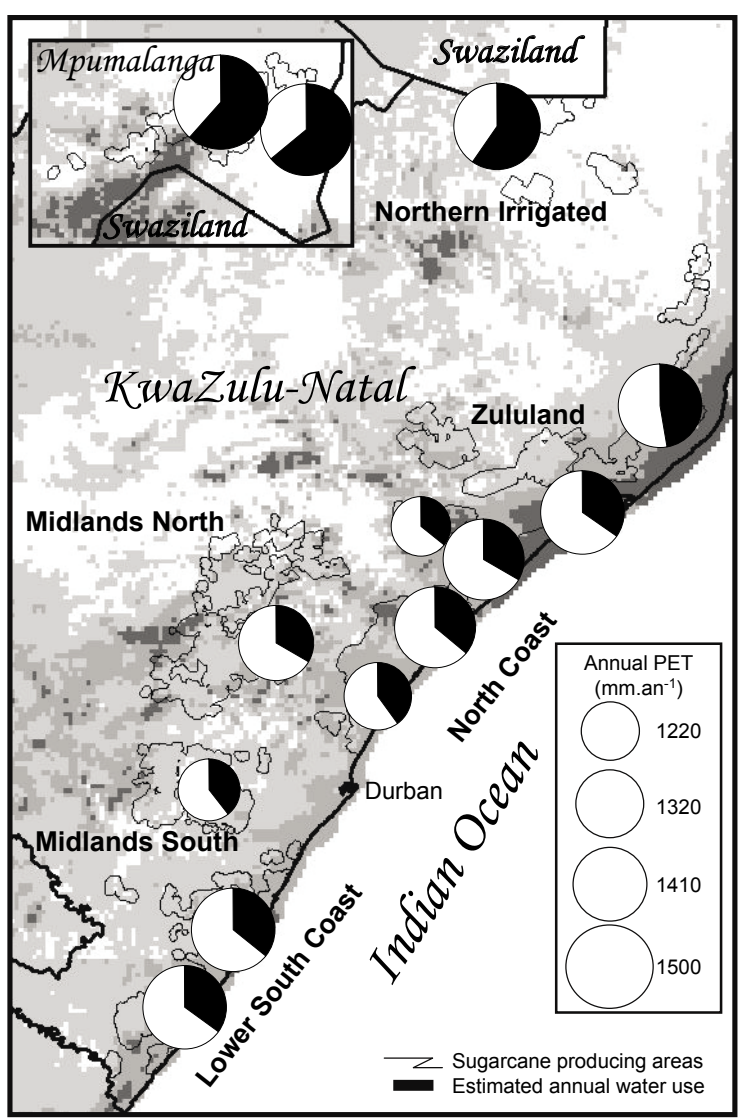

Figure 2 (top)

A spatial distribution of annual estimated sugar-cane water use (black areas in pie charts) relative to mean annual potential evapotranspiration (PET, indicated by the size of each pie chart). The grey scale background reflects areas under similar mean annual precipitations (Schulze, 1997).

The actual water use estimates for sugar-cane also reflect the fact that, for a large part of the growing season, the crop is not at full canopy and limited growth and water use take place, especially during the winter months. Water use $(w u)$ compared to MAP in the South Coast is relatively low; however, these figures were confirmed during simulations of the $A C R U$ hydrological model (Schulze, 1995), as well as from grower field records. Unutilised rain water can be expected to drain out of the profile, evaporate from the soil and foliage, or run off the surface. The proportions of these respective water balance components are unknown and further research is needed to enable sugar producers to perhaps utilise MAP more effectively.

\section{Conclusion}

In the introduction of this paper it was reasoned that actual water use (i.e. AET) of a crop is likely to be very different to potential water use (i.e. PET) owing to environmental constraints. The results shown in this paper, which are based on recorded crop production and a well researched, supported and field tested relationship between crop production and AET, provide strong evidence to support this reasoning. Therefore, comparisons of PET of different crops or land covers are of little value in determining potential hydrological impacts.

The average actual water use of sugar-cane determined in this study was $598 \mathrm{~mm} \cdot \mathrm{a}^{-1}$. This estimate, which includes irrigated cane, is well below the potential water use of $1400 \mathrm{~mm} \cdot \mathrm{a}^{-1}$ cited 


\begin{tabular}{|l|l|c|c|}
\hline \multicolumn{4}{|c|}{$\begin{array}{c}\text { TABLE 1 } \\
\text { Estimates of mean annual water use }(\boldsymbol{w u}) \text { and precipita- } \\
\text { tion (MAP) for different mill areas in South Africa }\end{array}$} \\
\hline Mill & Region & $\begin{array}{c}\text { wu } \\
\left(\mathbf{m m} \cdot \mathbf{a}^{-1}\right)\end{array}$ & $\begin{array}{c}\text { MAP } \\
\left(\mathbf{m m} \cdot \mathbf{a}^{-1}\right)\end{array}$ \\
\hline Komati & Mpumalanga & 1016 & 581 \\
\hline Malelane & Mpumalanga & 995 & 723 \\
\hline Pongola & Northern Irrigated & 914 & 610 \\
\hline Amatikulu & Zululand & 487 & 1029 \\
\hline Entumeni & Zululand & 440 & 977 \\
\hline Felixton & Zululand & 593 & 1043 \\
\hline Umfolozi & Zululand & 705 & 930 \\
\hline Darnall & North coast & 531 & 1024 \\
\hline Maidstone & North coast & 528 & 998 \\
\hline Gledhow & North coast & 528 & 1010 \\
\hline Noodsberg & Midlands North & 472 & 900 \\
\hline Union Coop & Midlands North & 499 & 900 \\
\hline Eston & Midlands South & 497 & 833 \\
\hline Sezela & South coast & 538 & 983 \\
\hline Umzimkulu & South coast & 521 & 1000 \\
\hline
\end{tabular}

in other studies. It is apparent that the availability of soil water is limiting in the evapotranspiration process for rain-fed sugar-cane in South Africa. When soil water availability is limiting:

- Differences between the AET of different crops are likely to be small even though the PET rates of the crops may be relatively larger, and furthermore,

- The below-ground rooting characteristics of different crops, which affect availability of soil and below-ground water, are likely to be very important determinants of hydrological impacts, probably more important than any differences in PET rates.

The use of PET comparisons to determine potential streamflow reduction activities (SFRAs) is, therefore, over-simplified. Whether there are any significant differences between the actual water use of different crops or land covers and whether or not these will manifest as significant impacts on water availability to competing users will require systems analyses with process-based and representative hydrological models. Such models should, amongst other things, account for the impacts of water availability on the evapotranspiration process. This study provides a benchmark of actual sugar-cane water use, which will be valuable in any such modelling exercise.

\section{Acknowledgements}

Data on crop production and areas under cane were provided by the South African Cane Growers Association. Several SASRI extension officers were consulted to assist with estimates on cane losses and percentage areas under seed cane schemes. Drs. Frikkie Botha and Carolyn Baker from SASRI are thanked for their inputs and support in this paper.

\section{References}

ACOCKS JPH (1975) Veld Types of South Africa ( $2^{\text {nd }}$ edn.). DJB Killick (ed.) Mem. Bot. Surv. S. Afr. 40128.

BEZUIDENHOUT CN (2005) Development and Evaluation of ModelBased Operational Yield Forecasts in the South African Sugar Industry. Unpublished Ph.D. Thesis, School of Bioresources Engineering \& Environmental Hydrology, University of KwaZulu-Natal, Pietermaritzburg. 146 pp.
BRZESOWSKY WJ and VAN VILSTEREN AEM (1988) An economic-evaluation of sugar-cane production under different watersupply systems in Thailand. Agric. Water Manage. 13 (1) 83-91.

CHEEROO-NAYAMUTH FC, ROBERTSON MJ, WEGENER MK and NAYAMUTH ARH (2000) Using a simulation model to assess potential and attainable sugar cane yield in Mauritius. Field Crops Res. 66 (3) 225-243.

COOMBS J (1984) Sugar-cane as an energy crop. Biotechnol. Gen. Eng. Rev. 1 311-345.

EGAN BT (1968) Post-harvest deterioration losses in sugar cane in Queensland. Proc. $13^{\text {th }}$ Congress of the Int. Soc. Sugar Cane Technol. Taiwan. 1729-1734,

EVENSEN CI, MUCHOW RC, ELSWAIFY A and OSGOOD RV (1997) Yield accumulation in irrigated sugar-cane 1. Effect of crop age and cultivar. Agron J. 89 (4) 638-646.

HARGREAVES GL and SAMANI ZA (1985) Reference crop evapotranspiration from temperature. Trans of Am. Soc. Agr. Eng. 1 96-99.

HEMAKUMARA HM, CHANDRAPALA L and MOENE AF (2003) Evapotranspiration fluxes over mixed vegetation areas measured from large aperture scintillometer. Agric. Water. Manage. 58 109122 .

KRUGER FJ, BOSCH JM, EVERSON C and BURGER C (2000) LandBased Activities that may be Declared Stream Flow Reduction Activities in terms of Section 36 of the National Water Act (Draft 1). Report to the Sub-Directorate: Stream Flow Reduction Activities of the Department of Water Affairs and Forestry, South Africa.

LEGENDRE BL and BURNER DM (1995) Biomass production of sugarcane cultivars and early-generation hybrids. Biomass \& Bioenergy 8 (2) 55-61.

LIONNET GRE (1986) Post-harvest deterioration of whole stalk sugarcane. Proc $60^{\text {th }}$ Annual SASTA Congress. Durban, South Africa. 52-57.

LUMSDEN TG, LECLER NL and SCHULZE RE (1998) Simulation of sugarcane yield at the scale of a mill supply area. Proc. 72th South African Sugar Technologists' Association Congress. Durban, South Africa. 12-17.

McGLINCHEY MG and INMAN-BAMBER NG (1996) Predicting sugarcane water use with the Penman-Monteith equation. Proc. Evapotrans. Irrig. Sched. Am. Soc. Agric. Eng.. San Antonio, USA. 592-597

MUCHOW RC, SPILLMAN MF, WOOD AW and THOMAS MR (1994) Radiation interception and biomass accumulation in a sugarcane crop grown under irrigated tropical conditions. Aust. J. Agric. Res. 45 (1) 37-49.

ROBERTSON MJ, WOOD AW and MUCHOW RC (1996) Growth of sugarcane under high input conditions in tropical Australia 1. Radiation use, biomass accumulation and partitioning. Field Crops Res. 48 (1) $11-25$.

SASRI EXTENSION DEPARTMENT (2005) Personal communication. Mt. Edgecombe, South Africa.

SCARPARI MS and DE BEAUCLAIR EGF (2004) Sugarcane maturity estimation through edaphic-climatic parameters. Sci. Agric. (Piracicaba, Braz.) 61 (5) 486-491.

SCHULZE RE (1995) Hydrology and Agrohydrology: A Text to Accompany the ACRU 3.00 Agrohydrological Modelling System. WRC Report No. TT 69/95. Water Research Commission, Pretoria, South Africa. $552 \mathrm{pp}$.

SCHULZE RE (1997) South African Atlas of Agrohydrology and Climatology. WRC Report No. TT 82/96. Water Research Commission, Pretoria, South Africa.

SINGELS A and BEZUIDENHOUT CN (2002) A new method of simulating dry matter partitioning in the CANEGRO sugarcane model. Field Crops Res. 78 (2-3) 151-164.

THOMPSON GD (1976) Water use by sugarcane. S. Afr. Sugar J. 60 598-600, 629-635.

WOOD RA, DU TOIT JL (1972) Deterioration losses in whole-stalk sugarcane. Proc. 46 th Annu. SASTA Congress. Durban, South Africa. 151-157

WYNNE AT (2001) Delivery efficiencies and cane quality in the South African sugar industry: Benchmarking and penalty allocations. Proc. S. Afr. Sugar Technol. Assoc. 75 38-42, Durban, South Africa, ISSN 1028-3781. 